\title{
LETTER \\ CIRCULAR \\ 1128
}

NBS Policy

on Use of

Its Name in

Advertising

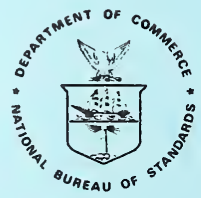

U.S. DEPARTMENT

OF COMMERCE

National Bureau of Standards 
The name of the National Bureau of Standards (NBS) is sometimes used in advertising by commercial firms in a manner contrary to Government regulations and inconsistent with NBS policy. This brochure cites these regulations, delineates NBS policy, and provides guidance on compliance in typical situations.

FEDERAL REGULATIONS AND NBS POLICY

The official policy of NBS regarding the use of its name in advertising can be found in Section 200.113 of Title 15 of the Code of Federal Regulations:

"As the national standards laboratory of the United States, NBS maintains and establishes the primary standards from which measurements in science and industry ultimately derive. It is therefore sometimes desirable for manufacturers or users of measurement standards to make appropriate reference to the relationship of their calibrations to NBS calibrations. The following considerations must be borne in mind, and shall be understood as constituting an agreement on the part of the NBS customer to be bound thereby in making reference to NBS calibration and test reports.

"The results of calibrations and tests performed by NBS are intended solely for the use of the organization requesting them, and apply only to a particular device or specimen at the time of its test. The results shall not be used to indicate or imply that they are applicable to other similar items. In addition, such results must not be used to indicate or imply that NBS approves, recommends, or endorses the manufacturer, the supplier, or the user of such devices or specimens, or that NBS in any way "guarantees" the later performance of items after calibration or test. 
"NBS declares it to be in the national interest that it maintain an impartial position with respect to any commercial product. Advertising the findings on a single instrument could be misinterpreted as an indication of performance of other instruments of identical or similar type. There will be no objection, however, to a statement that the manufacturer's primary standards have been periodically calibrated by NBS, if this is actually the case, or that the customer might arrange to have NBS calibrate the item purchased from the manufacturer.

"NBS does not approve, recommend, or endorse any proprietary product or proprietary material. No reference shall be made to NBS, or to reports or results furnished by NBS in any advertising or sales promotion which would indicate or imply that NBS approves, recommends, or endorses any proprietary product or proprietary material, or which has as its purpose an intent to cause directly or indirectly the advertised product to be used or purchased because of NBS test reports or results.

"In its own activities as a scientific institution NBS uses many different materials, products, types of equipment, and services. This use does not imply that NBS has given them a preferential position or a formal endorsement. Therefore, NBS discourages references, either in advertising or in the scientific literature, which identify it as a user of any proprietary product, material, or service. Occasionally effective communication of results by NBS to the scientific community requires that a proprietary instrument, product, or material be identified in an NBS publication. Reference in an NBS publication, report, or other document to a proprietary item does not constitute endorsement or approval of that item and such reference should not be used in any way apart from the context of the NBS publication, report, or document without the advance express written consent of NBS." 


\section{ADDITIONAL INFORMATION}

In order to clarify NBS policy further, three typical examples of prohibited advertising are given.

\section{EXAMPLE 1}

The XYZ Instrument Company reads an NBS technical paper in the open literature describing the design of a new type of instrument developed as part of an NBS research project. XYZ likes the design and decides to manufacture and sell an instrument based on this design, which they refer to as an "XYZ/NBS Instrument" both in their advertising and on the front panel of the instruments.

COMMENTARY: While NBS encourages commercial firms to utilize the results of NBS research to the greatest extent possible, the use of NBS's name in association with a proprietary product in that manner is prohibited! Even if the advertising copy and product literature were to make clear NBS's lack of involvement in the commercial venture, the possible implication that NBS is involved with this particular product is contrary to the policy stated above that NBS maintain an impartial position with respect to commercial products and also causes concern on the part of the manufacturers of competing instruments.

RECOMMENDATION: In this case, the manufacturer should have limited mention of NBS to stating that XYZ's design of the instrument is based on technical information published by NBS (and reference the appropriate technical paper) or based on an NBS design. 
EXAMPLE 2

A manufacturer labels a product it manufactures as "NBS traceable" or prominently displays this phrase in its advertising.

COMMENTARY: Many Federal regulations and contracts require regulated organizations or contractees to demonstrate that the measurements that they make are "traceable" to national standards. NBS encourages this practice but at the same time cannot condone the prominent display of its name on proprietary products or in the advertising of them. This particular use of NBS's name clearly implies NBS's endorsement contrary to our policy as stated above.

RECOMMENDATION: The manufacturer in this case could have described in some detail how their product is calibrated. This could include a discussion of how their laboratory standards are related to national standards through direct

Plibration by NBS or indirectly through an interediate calibration laboratory. As long as this description is factual and the NBS name is not prominently displayed, NBS would encourage such practice.

\section{EXAMPLE 3}

An organization claims by virtue of NBS calibration or test reports, that NBS "certifies" its standards.

COMMENTARY: NBS does not "certify" customer standards or products, since the word "certify" carries a connotation of a warranty or guarantee. Obviously NBS cannot warrant or guarantee the quality or reliability of standards or 


\section{0}

products calibrated by NBS once they leave NBS following calibration. Even high quality standards do drift with time, and NBS test reports make clear that the value assigned to a calibrated standard is only valid in a rigorous sense at the time that the calibration was performed at NBS.

RECOMMENDATION: Organizations should limit the use of NBS's name to factual statements such as "Our standard cells are submitted to NBS for recalibration at intervals of approximately two years."

FOR ADDITIONAL INFORMATION, CONTACT:

Office of the Legal Adviser - National Bureau of Standards

-Washington, DC 20234 (301) $921-2425$

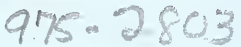

or

Office of Measurement Services

National-Bureau of Standards.

Washington, DC 20234 (301) 921-2805 4002 


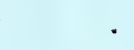

- 
